\title{
The urban-remote divide for Indigenous perinatal outcomes
}

\author{
Simon Graham, Lisa R Jackson Pulver, Yueping Alex Wang, Paul M Kelly, Paula J Laws, Narelle Grayson and Elizabeth A Sullivan
}

T he maternal and perinatal outcomes of Indigenous women and their babies have consistently been shown to be poorer than those of non-Indigenous women and their babies. ${ }^{1,2}$ In Australia, the literature has predominantly compared the Indigenous population with the non-Indigenous population, treating Indigenous peoples as a homogeneous population. ${ }^{2,3}$ However, recent Australian research has shown that the remoteness of places where mothers live affects their babies' risk of adverse perinatal outcomes, such as being small for gestational age and stillbirth (fetal death). ${ }^{4,5}$

A range of poorer perinatal outcomes, ${ }^{1-6}$ such as low birthweight, ${ }^{1}$ preterm birth ${ }^{3}$ and stillbirth (fetal death) ${ }^{1}$ are affected by certain characteristics of the mother, such as age, maternal nutrition and parity, ${ }^{7}$ smoking status, ${ }^{8-10}$ hypertension ${ }^{11}$ and diabetes. ${ }^{12}$ Another indicator of a poor perinatal outcome is a 5-minute Apgar score of less than seven. We examine each of these maternal characteristics and perinatal outcomes in this article.

In 2004, 8904 Indigenous women gave birth in Australia, accounting for $3.6 \%$ of all women who gave birth. ${ }^{13}$ We investigated the association of the remoteness category of the mothers' place of residence with babies' perinatal outcomes. As we recognise that the Indigenous population is heterogeneous, our focus was to look within the Indigenous population at perinatal health outcomes rather than comparing them with the nonIndigenous population.

\section{METHODS}

Data were obtained from the National Perinatal Data Collection (NPDC), a populationbased dataset of all births in Australia of at least 20 completed weeks' gestation or at least $400 \mathrm{~g}$ birthweight. The NPDC is compiled from state and territory perinatal data collections. Women identified as Indigenous who gave birth during 2001-2004 were included in this study. In 2001-2004, 35264 of all 1006284 mothers who gave birth in Australia were identified as Indigenous. Of these, 24 were excluded from the study because the remoteness category of their place of residence was unknown.

Data included demographic characteristics (including maternal age, smoking status and remoteness category) and perinatal out-

\section{ABSTRACT}

Objective: To determine whether remoteness category of residence of Indigenous women affects the perinatal outcomes of their newborn infants.

Design and participants: A population-based study of 35240 mothers identified as Indigenous and their 35658 babies included in the National Perinatal Data Collection in 2001-2004.

Main outcome measures: Australian Standard Geographical Classification remoteness category, birthweight, Apgar score at 5 minutes, stillbirth, gestational age and a constructed measure of perinatal outcomes of babies called "healthy baby" (live birth, singleton, 37-41 completed weeks' gestation, 2500-4499 g birthweight, and an Apgar score at 5 minutes $\geqslant 7$ ).

Results: The proportion of healthy babies in remote, regional and city areas was $74.9 \%$, $77.7 \%$ and $77.6 \%$, respectively. After adjusting for age, parity, smoking and diabetes or hypertension, babies born to mothers in remote areas were less likely to satisfy the study criteria of being a healthy baby (adjusted odds ratio [AOR], $0.87 ; 95 \% \mathrm{Cl}, 0.81-0.93$ ) compared with those born in cities. Babies born to mothers living in remote areas had higher odds of being of low birthweight (AOR, 1.09; 95\% Cl, 1.01-1.19) and being born with an Apgar score $<7$ at 5 minutes (AOR, 1.63; 95\% Cl, 1.39-1.92).

Conclusions: Only three in four babies born to Indigenous mothers fell into the "healthy baby" category, and those born in more remote areas were particularly disadvantaged. These findings demonstrate the continuing need for urgent and concerted action to address the persistent perinatal inequity in the Indigenous population.

MJA 2007; 186: 509-512

comes (including low birthweight $[<2500 \mathrm{~g}]$, low Apgar score at 5 minutes $[<7]$, preterm birth $[<37$ completed weeks' gestation], and stillbirth). We also examined four specific medical conditions associated with poor perinatal outcomes: gestational diabetes, diabetes mellitus, pregnancyinduced hypertension and essential hypertension. For the purpose of this article, we will refer to these collectively as "diabetes or hypertension".

We constructed a summary variable, "healthy baby". To be classified as a healthy baby, infants needed to meet all of the following criteria: live birth, singleton, 3741 completed weeks' gestation, birthweight of 2500-4499 g and an Apgar score at 5 minutes of seven or higher.

We examined only mothers identified in the collection as being of Aboriginal and/or Torres Strait Islander descent and reported here as Indigenous mothers. The collection does not include information about the fathers' Indigenous status, so babies born to an Indigenous father and a non-Indigenous mother cannot be identified. Data on smoking in pregnancy were available for only five states and territories in Australia, and the pattern of smoking status and its association with remoteness category of place of residence may vary according to the state or territory. Development of data on diabetes or hypertension in pregnancy is ongoing to enhance its quality.

\section{Classification of remoteness}

Data on the geographical location of the usual residence of the mother were provided as postcode and mapped to levels of remoteness by means of the Australian Standard Geographical Classification (ASGC) remoteness structure. ${ }^{14}$ After preliminary analysis, remoteness was grouped into three categories:

- Cities (the ASGC major cities category);

- Regional (comprising the ASGC inner and outer regional categories); and

- Remote (comprising the AGSC remote and very remote categories).

\section{Statistical analysis}

Univariate and multivariate logistic regression models were used to predict the probability of perinatal outcomes. Odds ratios, 
adjusted odds ratios and 95\% confidence intervals were calculated. Data were analysed with SPSS software (version 14.0; SPSS Inc, Chicago, Ill, USA) and Microsoft Excel (version 2003; Microsoft Corporation Redmond, Wash, USA).

\section{Ethical approval}

Ethical approval was granted by the Human Research Ethics Committees at the University of New South Wales and the Australian National University.

\section{RESULTS}

Women who identified as Indigenous, and their pregnancy characteristics

For the period 2001-2004, 35658 babies were born to 35240 Indigenous women in Australia $(3.5 \%$ of all births in Australia between 2001-2004). Box 1 shows that most Indigenous women who gave birth between 2001 and 2004 lived in regional (44.3\%) or remote areas $(32.1 \%)$ rather than city areas (23.6\%).

Box 1 shows that women aged less than 20 years accounted for $22.5 \%$ of Indigenous mothers in 2001-2004. A higher proportion of teenage Indigenous mothers lived in remote areas than in regional or city areas. However, a higher proportion of first-time mothers aged 35 years or older resided in city areas than in regional or remote areas. A higher proportion of multiparous teenage Indigenous mothers lived in remote areas than in city and regional areas.

Mothers living in regional areas were more likely to be smokers than those living in city areas (odds ratio [OR], 1.25; 95\% CI, 1.16-1.33). However, there was no significant difference in smoking status between mothers who lived in remote and city areas (OR, 0.99; 95\% CI, 0.93-1.06). After adjusting for maternal age, Indigenous mothers who lived in regional areas had a higher smoking rate than those who lived in city areas and remote areas (Box 1).

A higher proportion of mothers who lived in remote areas had diabetes or hypertension than mothers who lived in regional or city areas (Box 1).

\section{Perinatal outcomes}

A higher proportion of low-birthweight babies ( $<2500 \mathrm{~g}$ ) were born to mothers in remote areas compared with regional and city areas (Box 2). A multivariate analysis showed that babies born to mothers in remote areas had higher odds of low birth-

\begin{tabular}{|c|c|c|c|c|}
\hline & City & Regional & Remote & Total \\
\hline All Indigenous mothers & $8321(23.6 \%)$ & $15616(44.3 \%)$ & 11303 (32.1\%) & 35240 \\
\hline \multicolumn{5}{|l|}{ Age } \\
\hline No. with data & 8321 & 15610 & 11295 & 35226 \\
\hline$<20$ years & $19.9 \%$ & $21.4 \%$ & $25.9 \%$ & $22.5 \%$ \\
\hline 20-24 years & $29.4 \%$ & $31.4 \%$ & $31.9 \%$ & $31.1 \%$ \\
\hline $25-29$ years & $24.5 \%$ & $24.7 \%$ & $22.1 \%$ & $23.8 \%$ \\
\hline $30-34$ years & $17.3 \%$ & $15.8 \%$ & $13.4 \%$ & $15.4 \%$ \\
\hline $35-39$ years & $7.4 \%$ & $5.7 \%$ & $5.6 \%$ & $6.1 \%$ \\
\hline \multirow[t]{2}{*}{$40+$ years } & $1.5 \%$ & $1.0 \%$ & $1.0 \%$ & $1.1 \%$ \\
\hline & \multicolumn{4}{|c|}{$\chi^{2}, 215.8 ; d f, 10 ; P<0.01$} \\
\hline \multicolumn{5}{|l|}{ Parity } \\
\hline No. with data & 8314 & 15597 & 11293 & 35204 \\
\hline 0 & $33.4 \%$ & $29.6 \%$ & $28.3 \%$ & $30.1 \%$ \\
\hline 1 to 3 & $51.6 \%$ & $53.9 \%$ & $54.3 \%$ & $53.5 \%$ \\
\hline \multirow[t]{2}{*}{4 or more } & $15.0 \%$ & $16.4 \%$ & $17.3 \%$ & $16.3 \%$ \\
\hline & \multicolumn{4}{|c|}{$\chi^{2}, 65.9 ; \mathrm{df}, 4 ; P<0.01$} \\
\hline \multicolumn{5}{|l|}{ Smoking* } \\
\hline No. with data & 5843 & 8081 & 7546 & 21470 \\
\hline Did not smoke & $48.5 \%$ & $43.0 \%$ & $48.7 \%$ & $46.5 \%$ \\
\hline \multirow[t]{2}{*}{ Smoked } & $51.5 \%$ & $57.0 \%$ & $51.3 \%$ & $53.5 \%$ \\
\hline & \multicolumn{4}{|c|}{$\chi^{2}, 63.2 ; \mathrm{df}, 2 ; P<0.01$} \\
\hline $\begin{array}{l}\text { Age-standardised smoking } \\
\text { rate }\end{array}$ & $51.6 \%$ & $57.0 \%$ & $51.4 \%$ & \\
\hline \multicolumn{5}{|l|}{ Diabetes or hypertension } \\
\hline No. with data & 8227 & 15590 & 11301 & 35118 \\
\hline No & $88.0 \%$ & $89.0 \%$ & $87.0 \%$ & $88.1 \%$ \\
\hline \multirow[t]{2}{*}{ Yes } & $10.8 \%$ & $10.9 \%$ & $13.0 \%$ & $11.5 \%$ \\
\hline & \multicolumn{4}{|c|}{$\chi^{2}, 33.6 ; d f, 2 ; P<0.01$} \\
\hline
\end{tabular}

weight compared with babies born to city mothers (adjusted odds ratio [AOR], 1.09; 95\% CI, 1.01-1.19) (Box 2). Multivariate analysis also showed that diabetes or hypertension (AOR, 1.44; 95\% CI, 1.321.57 ) and smoking (AOR, 1.80; 95\% CI, 1.66-1.95) were associated with low birthweight.

A higher proportion of babies with a low Apgar score at 5 minutes $(<7)$ were born to mothers who lived in remote areas compared with regional or city areas. After adjusting for maternal age, parity, smoking and diabetes or hypertension, babies born to mothers in regional areas (AOR, 1.28; 95\% CI, 1.09-1.50) and remote areas (AOR, 1.63; 95\% CI, 1.39-1.92) were more likely to have a low Apgar score at 5 minutes compared with city babies (Box 2).

\section{Mother's characteristics and perinatal outcomes}

Most Indigenous babies (76.7\%) were classified as "healthy baby". Healthy babies were less likely to be born to mothers in remote areas than in regional and city areas (Box 3). After adjusting for maternal age, parity, smoking and diabetes or hypertension, babies born to mothers in remote areas had lower odds of being a healthy baby (AOR, 0.87 ; 95\% CI, 0.81-0.93) than those born to mothers in city areas. (Box 3).

In the final multivariate logistic regression model, diabetes or hypertension and smoking were also independently associated with having a healthy baby. Diabetes or hypertension almost halved the odds of a mother having a healthy baby (AOR, 0.55; 95\% CI, 0.51-0.59). Smoking during pregnancy also 


\begin{tabular}{|c|c|c|c|}
\hline \multicolumn{4}{|c|}{$\begin{array}{l}2 \text { Perinatal outcomes of babies of Indigneous mothers by remoteness area, } \\
\text { Australia 2001-2004 }\end{array}$} \\
\hline Perinatal outcomes & Number (\%) & Odds ratio $(95 \% \mathrm{Cl})$ & $\begin{array}{l}\text { Adjusted odds ratio* } \\
\qquad(95 \% \mathrm{Cl})\end{array}$ \\
\hline \multicolumn{4}{|l|}{ Low birthweight } \\
\hline City & 8419 (13.3\%) & 1.00 & 1.00 \\
\hline Regional & $15746(13.1 \%)$ & $0.99(0.91-1.07)$ & $0.99(0.91-1.07)$ \\
\hline Remote & 11385 (14.2\%) & $1.08(1.00-1.17)$ & $1.09(1.01-1.19)$ \\
\hline \multicolumn{4}{|l|}{ Preterm birth } \\
\hline City & $8443(14.0 \%)$ & 1.00 & 1.00 \\
\hline Regional & 15793 (13.3\%) & $0.94(0.87-1.01)$ & $0.93(0.86-1.00)$ \\
\hline Remote & 11402 (14.6\%) & $1.05(0.97-1.14)$ & $1.02(0.94-1.11)$ \\
\hline \multicolumn{4}{|c|}{ Low Apgar score at 5 minutes } \\
\hline City & $8403(2.7 \%)$ & 1.00 & 1.00 \\
\hline Regional & $15728(3.4 \%)$ & $1.26(1.08-1.48)$ & $1.28(1.09-1.50)$ \\
\hline Remote & 11367 (4.3\%) & $1.61(1.37-1.89)$ & $1.63(1.39-1.92)$ \\
\hline \multicolumn{4}{|l|}{ Stillbirth ${ }^{\dagger}$} \\
\hline City & $8443(1.1 \%)$ & 1.00 & 1.00 \\
\hline Regional & $15798(1.1 \%)$ & $0.99(0.77-1.27)$ & $0.97(0.76-1.26)$ \\
\hline Remote & $11417(1.3 \%)$ & $1.12(0.89-1.49)$ & $1.16(0.89-1.51)$ \\
\hline
\end{tabular}

*Adjusted for age, parity, smoking and diabetes or hypertension. $†$ Fetal death of at least 20 completed weeks' gestation or at least $400 \mathrm{~g}$ birthweight.

\section{3 "Healthy baby"* measure for babies of Indigenous mothers by remoteness area, Australia 2001-2004}

\begin{tabular}{lccccc} 
& & & \multicolumn{3}{c}{ Healthy baby } \\
\cline { 4 - 6 } $\begin{array}{l}\text { Remoteness } \\
\text { area }\end{array}$ & Total no. & $\begin{array}{c}\text { Not healthy } \\
\text { baby }\end{array}$ & & $\begin{array}{c}\text { Odds ratio } \\
(95 \% \mathrm{Cl})\end{array}$ & $\begin{array}{c}\text { Adjusted odds ratio } \\
(95 \% \mathrm{Cl})\end{array}$ \\
\hline City & 8443 & $22.4 \%$ & $77.6 \%$ & 1.00 & 1.00 \\
Regional & 15798 & $22.3 \%$ & $77.7 \%$ & $1.01(0.94-1.07)$ & $1.01(0.94-1.07)$ \\
Remote & 11417 & $25.1 \%$ & $74.9 \%$ & $0.86(0.81-0.92)$ & $0.87(0.81-0.93)$ \\
\hline
\end{tabular}

* A "healthy baby" is classified as a live-born singleton of 37-41 completed weeks' gestation, with a birthweight of 2500-4499 g, and having an Apgar score at 5 minutes of 7 or more. † Adjusted for age, parity, smoking and diabetes or hypertension.

significantly reduced the odds of a mother having a healthy baby (AOR, 0.75; 95\% CI, $0.70-0.80)$.

\section{DISCUSSION}

This study suggests that, in a context of overall perinatal disadvantage for Indigenous mothers, the additional factor of remoteness is a minor but significant factor associated with poorer perinatal outcomes for babies. Indigenous mothers living in remote areas were 14\% less likely to have a healthy baby than mothers living in regional or city areas. This study raises questions as to whether remoteness is itself the risk factor, or a proxy for other factors on perinatal outcomes. ing antenatal programs. Future strategies and programs need to consider the different risk profiles or antenatal needs of Indigenous populations rather than applying one type of program uniformly to the Indigenous population.

Although Indigenous mothers who lived in remote areas were less likely to smoke, they were more likely to have diabetes or hypertension, be younger and have a higher parity than Indigenous mothers in the two other areas. National reporting has highlighted the association between smoking and low birthweight and preterm birth. ${ }^{9,10}$ Being a mother at the younger and older ends of the reproductive age range or with diabetes or hypertension have also been shown to be associated with poor perinatal outcomes. ${ }^{11,13,15,16}$ This partially explains why there is higher prevalence of poorer perinatal outcomes in babies of Indigenous mothers who lived in remote areas compared with the other areas.

A limitation of our study is the potential underascertainment of Indigenous status in the NPDC. A national review of Indigenous ascertainment in the NPDC is currently being conducted by the AIHW, and is expected to be published in the second half of 2007. Previous studies found the quality of data on Indigenous status in collections using hospital separation data has been found to be wanting. ${ }^{17,18}$ The reported rate of unknown Indigenous status of $2.2 \%$ in the NPDC for 2001-2004 reflects the continuing challenge of identifying Indigenous status in large population and administrative collections.

Two central messages emerge from our data: first, yet another call for greater action for improving Indigenous health; and second, that likely systemic disadvantage, rather than just compromised or suboptimal pregnancy care, is responsible for some of the persistent inequity in perinatal outcomes of Indigenous mothers giving birth in Australia today. Our finding that one in four Indigenous babies do not meet our modest criteria for a healthy baby suggests that measures implemented to address perinatal inequity need urgent and concerted action to improve this unacceptable situation.

\section{ACKNOWLEDGEMENTS}

Simon Graham and Lisa Rae Jackson Pulver are Aboriginal Australians and all authors recognise the Land on which this work was done and acknowledge the contribution Indigenous Australians make to this important work. The Australian Institute of Health and Welfare is the funding body of the National Perinatal Data Collection and a 
major funding provider of the AlHW National Perinatal Statistics Unit. These data are a distillation of the work of many collectors and data analysts in the states and territories. Simon Graham conducted this study as a part of his scholarship in the Masters of Applied Epidemiology (MAE) degree at the Australian National University. The MAE program is funded by the Australian Department of Health and Ageing. Paul Kelly's salary is partly supported by the National Health and Medical Research Council.

\section{COMPETING INTERESTS}

None identified.

\section{AUTHOR DETAILS}

Simon Graham, BIS, Masters of Applied Epidemiology Candidate ${ }^{1,3}$

Lisa R Jackson Pulver, PhD, MPH,

GradDipAppEpi, Associate Professor ${ }^{2}$

Yueping Alex Wang, MB BS; MPH, Research Officer $^{3}$

Paul M Kelly, DTM\&H, PhD, FAFPHM, Associate Professor and Director ${ }^{1}$

Paula J Laws, BA(Hons), Research Officer ${ }^{3}$

Narelle Grayson, BA(Hons), Adjunct Research

Fellow ${ }^{3}$

Elizabeth A Sullivan, MB BS, MPH

MMed(Sexual Health), Director ${ }^{3}$ and Senior Lecturer $^{4}$

1 Master of Applied Epidemiology Program,

National Centre for Epidemiology and

Population Health, College of Medicine and

Health Sciences, Australian National University, Canberra, ACT.

2 Muru Marri Indigenous Health Unit, University of New South Wales, Sydney, NSW.

3 Australian Institute of Health and Welfare National Perinatal Statistics Unit, University of New South Wales, Sydney, NSW.

4 School of Women's and Children's Health, University of New South Wales, Sydney, NSW.

Correspondence: e.sullivan@unsw.edu.au

\section{REFERENCES}

1 Day P, Sullivan EA, Lancaster P. Indigenous mothers and their babies, Australia 1994-1996. Perinatal Statistics Series No. 8. Sydney: Australian Institute of Health and Welfare National Perinatal Statistics Unit, 1999. (AlHW Cat. No. PER 9.) http://www.npsu.unsw.edu.au/ ps8high.htm (accessed Apr 2007).

2 Westenberg L, Van der Klis K, Chan A, et al. Aboriginal teenage pregnancies compared with non-Aboriginal in South Australia 19951999. Aust N Z J Obstet Gynaecol 2002; 42: 187-192.

3 Chan A, Keane RJ, Robinson JS. The contribution of maternal smoking to preterm birth, small for gestational age and low birthweight among Aboriginal and non-Aboriginal births in South Australia. Med J Aust 2001; 174: 389-393.

4 Abdel-Latif ME, Bajuk B, Oei J, et al. Does rural or urban residence make a difference to neonatal outcome in premature birth? A regional study in Australia. Arch Dis Child Fetal Neonatal Ed 2006; 91: F251-F256.

5 Roberts CL, Algert CS. The urban and rural divide for women giving birth in NSW, 19901997. Aust N Z J Public Health 2000; 24: 291297.

6 Powell J, Dugdale AE. Obstetric outcomes in an Aboriginal community: a comparison with the surrounding rural area. Aust J Rural Health 1999: 21: 624-630.

7 Moshin M, Wong F, Bauman A, et al. Maternal and neonatal factors influencing premature birth and low birthweight in Australia. J Biosoc Sci 2003; 35: 161-174.

8 Sayers S, Powers J. Risk factors for Aboriginal low birthweight, intrauterine growth retardation and preterm birth in Darwin Health Region. Aust N Z J Public Health 1997; 21: 524-530.

9 Laws PJ, Grayson N, Sullivan EA. Smoking and pregnancy. Sydney: AlHW National Perinatal Statistics Unit, 2006. (AlHW Cat. No. PER 33.) http://www.npsu.unsw.edu.au/smoking 2006.htm (accessed Apr 2007).

10 Horta BL, Victora CG, Menezes AM, et al. Low birthweight, preterm births and intrauterine growth retardation in relation to maternal smoking. Paediatr Perinat Epidemiol 1997; 11: 140-151.

11 Roberts CL, Algert CS, Morris JM, et al. Hypertensive disorders in pregnancy: a populationbased study. Med J Aust 2005; 182: 332-335

12 Gunton JE, McElduff A, Sulway M, et al. Outcome of pregnancies complicated by pre-gestational diabetes mellitus. Aust N Z J Obstet Gynaecol 2000; 40: 38-43.

13 Laws PJ, Grayson N, Sullivan EA. Australia's mothers and babies 2004. Perinatal statistics series no. 18. Sydney: AIHW National Perinatal Statistics Unit, 2006. (AlHW cat. No. PER 34.) http://www.npsu.unsw.edu.au/ps18high.htm (accessed Apr 2007).

14 Australian Bureau of Statistics. Australian standard geographical classification (ASGC), 2001. Canberra: ABS, 2001. (ABS Cat. No. 1216.0.) http://www.abs.gov.au/Ausstats/ abs@.nsf/66f306f503e529a5ca25697e0017661f/ a3658d8f0ad7a9b6ca256ad4007f1c42!OpenDocument (accessed Apr 2007).

15 Castles A, Adams CK, Melvin CL, et al. Effects of smoking during pregnancy. Five meta-analyses. Am J Preventive Med 1999; 16: 208-215.

16 Van der Klis KA, Westenberg L, Chan A, et al. Teenage pregnancy: trends, characteristics and outcomes in South Australia and Australia. Aust N Z J Public Health 2002; 26: 125-131.

17 Jackson Pulver LR, Bush A, Ward J. Identification of Aboriginal and Torres Strait Islander women using an urban obstetric hospital. Aust Health Rev 2003; 26: 19-25.

18 Australian Institute of Health and Welfare. Improving the quality of Indigenous identification in hospital data. Health Services Series no. 25. Canberra: AlHW, 2005. (AlHW Cat. No. HSE 101.) http://www.aihw.gov.au/publications/ index.cfm/title/10222 (accessed Apr 2007).

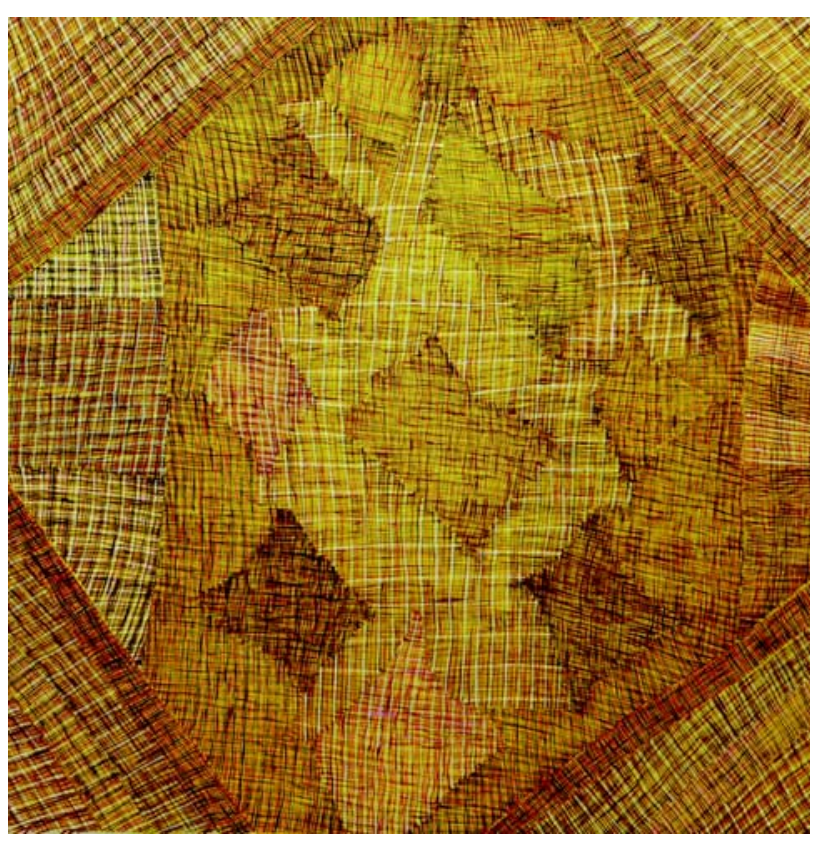

Artists: Regina Wilson (left) and Ningurra Napurrula (right) (from the Shalom Gamarada art exhibition - see page 551).

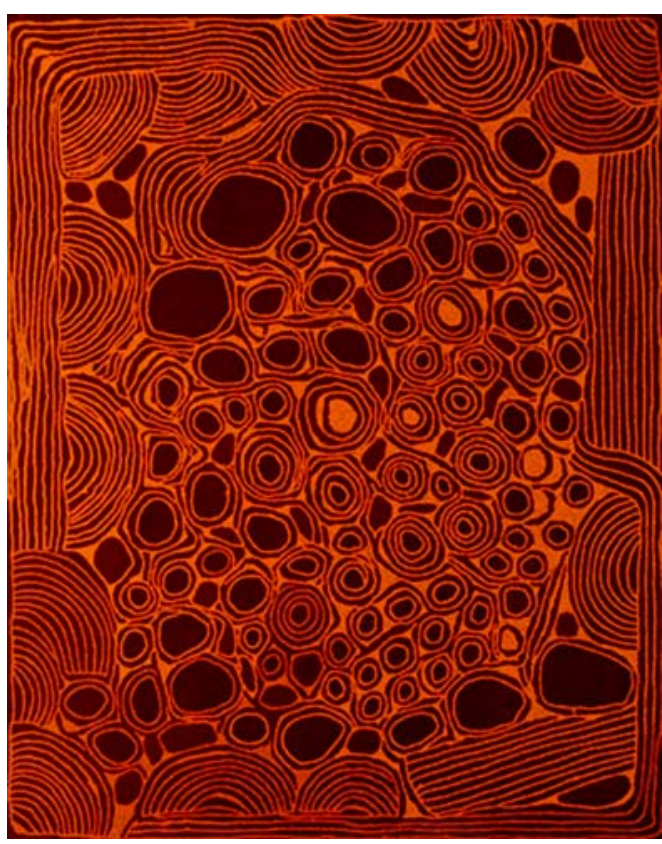

